\title{
CAPITALISMO Y PUEBLOS INDÍGENAS EN EL CHACO ARGENTINO: FORMAS Y DETERMINACIONES DE UNA SUBJETIVIDAD PRODUCTIVA
}

\section{Capitalism and indigenous people in the Argentinean Chaco: forms and determinations of a productive subjectivity JUAN INIIGO CARRERA* Y VALERIA IÑIGO CARRERA**}

\author{
Fecha de recepción: 28 de febrero de 2017 - Fecha de aprobación: 17 de abril de 2017
}

\section{Resumen}

Los pueblos indígenas del Chaco argentino constituyen una población trabajadora desplazada de la producción rural, al encontrarse cada vez más en exceso relativo para los requerimientos del capital. Este trabajo se propone abordar el proceso de progresiva mutilación de sus atributos productivos, a partir de desplegar sus determinaciones generales hasta alcanzar las formas concretas específicas con que estas se realizan en el caso considerado. Para ello partimos de desarrollar las determinaciones materiales del trabajo como condición inherente a la vida humana, avanzando luego sobre la determinación de la subjetividad productiva humana propia del modo de producción capitalista. Nos enfrentamos así a la privación, impuesta sobre porciones significativas de la población trabajadora, del ejercicio de su capacidad para participar activamente en el proceso de producción y consumo social. Seguidamente desplegamos las expresiones que encuentra la mutilación de los atributos de los indígenas como sujetos del proceso de trabajo: la limitación en su participación -como productores independientes y trabajadores estacionales- en los distintos cultivos, la caída del salario, la venta de los productos del trabajo doméstico por debajo de su valor, su constitución generalizada en beneficiarios de programas sociales de asistencia.

Palabras clave: capitalismo, pueblos indígenas, subjetividad productiva, Chaco argentino.

\begin{abstract}
The indigenous people of the Argentinean Chaco constitute a laboring population displaced from rural production, as it increasingly becomes in relative excess for capital's requirements. This paper aims to address the process of progressive mutilation of their productive attributes, starting by unfolding its general determinations up to reaching the specific concrete forms in which the former realize themselves in the case under consideration. Consequently, we start by developing the material determinations of labor as an inherent condition for human life, to advance then into the determination of human productive subjectivity within the capitalist mode of production. We thus face the deprivation imposed upon significant portions of the laboring population, to exercise their capacity to actively take part in the process of social production and consumption. Next we unfold the expressions taken by the mutilation of indigenous people's attributes as subjects of the labor process: the limitation in their participation -as independent producers and seasonal workers- in different crops, declining wages, the sale of domestic labor products below their value, their generalized constitution into beneficiaries of social assistance programs.
\end{abstract}

Keywords: capitalism, indigenous people, productive subjectivity, argentine Chaco

\footnotetext{
* Doctor Director e investigador del Centro para la Investigación como Crítica Práctica - CICP; docente e investigador de la Universidad de Buenos Aires, Buenos Aires, Argentina. Correo-e: jinigo@inscri.org.ar, juanbinigo@gmail.com

** Doctora Investigadora del Instituto de Investigaciones en Diversidad Cultural y Procesos de Cambio, Consejo Nacional de Investigaciones Científicas y Técninas/Universidad Nacional de Río Negro. San Carlos de Bariloche, Argentina. Artículo enmarcado en tesis de doctorado y proyecto de posdoctorado. Correo-e: v.inigocarrera@conicet.gov.ar
} 


\section{La cuestión y su enfoque}

La frontera agropecuaria se encuentra en pleno proceso de expansión en la región del Chaco argentino ${ }^{1}$. Este proceso se caracteriza por el ingreso de capitales aplicados a la producción agropecuaria en gran escala, fomentado mediante la implementación de políticas públicas de manejo de los recursos naturales y por la introducción de modificaciones en el ordenamiento territorial. Se caracteriza igualmente por presentar como contracara la expulsión de fuerza de trabajo de dicha producción, la emigración de la población rural, la deforestación y los procedimientos de desalojo contra indígenas y campesinos. ${ }^{2}$ De hecho, con sólo observar las condiciones concretas en que los pueblos indígenas del ámbito rural de la porción argentina del Gran Chaco ejercen su atributo humano de sujetos de la producción y el consumo sociales, resulta evidente la creciente mutilación que sufre esta subjetividad: participación constantemente decreciente en los cultivos como productores independientes y asalariados estacionales; caída del salario obtenido, que apenas alcanza a cubrir la reproducción física durante el periodo de trabajo; venta de los productos del trabajo artesanal y de los subproductos de la "marisca" (caza de pequeños animales del monte, pesca, recolección de frutos silvestres y miel) muy por debajo del precio al que luego circulan en el mercado; imposibilidad de acceder a los medios de vida si no es constituyéndose de manera generalizada en beneficiarios de programas sociales de asistencia a la pobreza y al desempleo.

Ante semejante mutilación, no cabe duda de que resultan acuciantes las acciones políticas que le hagan frente. Éstas pueden tomar muy distintas formas y plantearse muy distintos alcances. Pero la organización de cualquiera de ellas supone el conocimiento de las determinaciones concretas que objetivamente pone en juego y, en consecuencia, el conocimiento de sus propias potencias objetivas. Justamente, su diferenciación de partida va a radicar en el alcance con que el conocimiento que las rige haya dado cuenta de esas determinaciones y, por lo tanto, haya dado cuenta de su propia necesidad.

A primera vista puede parecer que no hay modo más concreto de responder acerca de los atributos de determinado sujeto social que atenerse a las expresiones manifiestas de esta subjetividad. Por ejemplo, explicar el modo en que dichos pueblos participan en la producción y el consumo sociales por su idiosincrasia, por la concepción que los sujetos en cuestión tienen de sí mismos respecto del movimiento general de la sociedad en que desenvuelven su vida. Más aún, este tipo de enfoque puede llegar a presentar como aval de su objetividad el fundar su explicación en la propia voz de los involucrados (p.e., Geertz, 1999). Sin embargo, por muy concretas que sean las expresiones con que un sujeto social se reconoce a sí mismo, la explicación de su subjetividad no puede agotarse en ella. La cuestión reside en preguntarse por las razones que hacen al sujeto reconocerse de un modo u otro. De hecho, la existencia más concreta se convierte en una pura abstracción si se la separa de sus determinaciones.

Frente a esta limitación se puede intentar una profundización en el análisis de las determinaciones en juego, explicando el curso seguido por los atributos de la subjetividad productiva en cuestión, por la función que le cabe desarrollar respecto del movimiento general del proceso de vida social (p.e., Cohen, 1988). 
Así, puede concebirse que, los pueblos indígenas podían reproducir su subjetividad productiva mientras esta cumplía una función en la acumulación de capital. Agotada esta funcionalidad, esa reproducción se ha tornado insostenible. Parece así que se ha avanzado en el conocimiento del objeto de la acción en su verdadera determinación concreta. Sin embargo, la relación puede interpretarse de manera opuesta: la destrucción de la subjetividad productiva de los pueblos indígenas se explica por la función que éstos cumplen en la reproducción del capital vía la sujeción de su reproducción al clientelismo político. En realidad, lo que la explicación funcional hace es reducir la determinación a la coexistencia, a partir de asignarle primacía a un polo respecto del otro según el criterio del investigador.

Bien podemos decir aquí que no hemos logrado aún traspasar el terreno de "Los ingleses, que gustan de considerar la primera forma empírica de manifestarse las cosas como el fundamento de éstas" (Marx, 2001: 331). Se puede intentar superar la barrera de la exterioridad de las relaciones entre las distintas formas concretas que se enfrenta concibiéndolas como interacciones entre esas formas, en las cuales ellas se determinan recíprocamente sobre la base de su autonomía relativa (p. e., Althusser, 1976). Parecería así que se ha dejado atrás la abstracción de lo concreto al abarcar la multiplicidad de sus determinaciones. Sin embargo, detengámonos un momento en el concepto metodológico de la "autonomía relativa". Este concepto lleva, primero, a preguntarse por ¿cuánta? y, segundo, a preguntarse por ¿cómo? Esto es, tomando el ejemplo clásico, si la estructura económica determina a la subjetividad política, pero ésta tiene una autonomía relativa frente a aquélla, por la cual a su vez determina el movimiento de la estructura, que a su vez reacciona sobre la subjetividad, que etc. Se llega lógicamente así a la inevitable conclusión de la indeterminación abstracta general, fuera de la impuesta por el arbitrio del investigador. Si hay en esta construcción algún carácter dialéctico no logra superar la exterioridad del "por una parte, por la otra parte" (Marx, s/f). Y, con ello, se cae nuevamente en la reducción de lo concreto a una abstracción, por muy complejas que parezcan las relaciones establecidas.

Nos encontramos, así, frente a la necesidad de encarar la cuestión de la subjetividad productiva específica de los pueblos indígenas del Chaco argentino desde un punto de vista metodológico radicalmente distinto. Partamos para ello de la razón específica misma del conocimiento científico: "toda ciencia sería superflua si la forma de manifestación y la esencia de las cosas coincidiesen directamente" (Marx, 1984: 1041). En consecuencia, nos enfrentamos a la determinación como el movimiento en que una existencia concreta portadora de una potencia alcanza su término, es decir, realiza su necesidad tomando la correspondiente forma concreta. En otras palabras, nos enfrentamos a la determinación como el proceso en que "la esencia de las cosas" se afirma mediante su propia negación en su "manifestación". Desde este punto de vista, no hay contenido que no exista bajo su forma concreta necesaria, ni forma concreta que no sea la realización de la necesidad de su contenido. Para ponerlo de inmediato respecto de las reducciones "economicistas" y "politicistas", toda relación económica se realiza necesariamente, o sea, existe en su movimiento, bajo la forma de una relación política; toda relación política tiene por contenido que realiza a una relación económica (Iñigo Carrera, J., 2012). 
Por lo tanto, el método dialéctico que aquí proponemos acompaña el desarrollo de las determinaciones de las cuales es portador nuestro objeto concreto, apuntando a "la reproducción de lo concreto por el camino del pensamiento" (Marx, 1971:21). De modo que partimos del análisis de dicho objeto concreto preguntándonos por las determinaciones de las cuales es portador, hasta enfrentar éstas bajo su forma más simple y general. Acompañamos entonces el despliegue de estas determinaciones hasta volver a enfrentarnos a nuestro concreto de partida, pero ahora como un concreto cuya potencialidad conocemos por haberla reproducido mediante el razonamiento (Iñigo Carrera, J., 1992, 2007, 2013).

Nos proponemos, pues, reconocer la unidad de las múltiples determinaciones del proceso en que los pueblos indígenas del Chaco se constituyen como un sujeto social concreto, de cuya especificidad debemos dar cuenta partiendo de la relación social general que rige la organización capitalista de la producción y el consumo sociales, hasta alcanzar la mediación que determina dicha especificidad por su condición de población indígena. $Y$ en este sentido, lo primero con que se enfrenta el análisis es el proceso de progresiva mutilación de los atributos productivos de la fuerza de trabajo indígena en la mencionada región al cual hemos hecho referencia en nuestro primer párrafo.

Sobre esta base, nuestra exposición parte desplegando de manera extremadamente sintética -dado el objetivo de nuestro trabajo- el reconocimiento de las determinaciones materiales del trabajo como condición inherente a la vida humana, para avanzar luego sobre la determinación de la subjetividad productiva humana como atributo de la relación social objetivada propia del modo de producción capitalista. Por este camino nos enfrentamos al hecho de la privación a porciones significativas de la población trabajadora, del ejercicio de su capacidad para participar activamente en el proceso de producción y consumo social. Alcanzado este punto en el desarrollo de la determinación general del modo de producción capitalista, pasamos a reconocer esta determinación bajo las formas concretas específicas que toma en las múltiples expresiones que encuentra la mencionada mutilación de los atributos de los indígenas como sujetos productivos sociales.

Resulta oportuno realizar un par de aclaraciones respecto del desarrollo que se va a presentar, para prevenir eventuales equívocos. Primero, la contraposición del camino metodológico propuesto respecto de los enfoques esencialistas, funcionalistas y de autonomía relativa referidos anteriormente no tiene simplemente un carácter general. Por el contrario, se extiende a todo lo largo de su curso y se renueva con cada paso que se avanza en el desarrollo del conocimiento del concreto objeto del estudio. En consecuencia, a cada paso puede surgirle al lector la demanda por que se exponga dicha contraposición bajo la forma de una discusión puntual con los otros enfoques metodológicos. Por ejemplo, que al desplegar las determinaciones respecto de la reproducción de la población indígena rural en condiciones de extrema miseria se explicite la discusión con la concepción de la sobreexplotación de la fuerza de trabajo de la teoría de la dependencia; o con la teoría de la racionalidad de la unidad económica campesina de la escuela de Chayanov. Sin embargo, la posibilidad de que tal discusión vaya más allá de un debate abstracto tiene como primera condición el 
despliegue positivo de la reproducción razonada de las determinaciones relevantes que se encuentran en el concreto objeto de la cuestión (Marx, 2001: 683 y 686); despliegue al que apunta el presente trabajo. $Y$ es claro que, una vez presentado dicho despliegue, la discusión de los múltiples aspectos específicos requeriría una extensión varias veces mayor a la que cabe aquí. De modo que este trabajo se propone como base necesaria para avanzar en el debate sobre la multiplicidad de formas concretas y enfoques teóricos en torno a ellas. Segundo, el enfoque propuesto no tiene un carácter interdisciplinario. Esto es, no parte de las categorías de la economía política para terminar en las de la antropología. Por el contrario, parte de enfrentar la determinación más simple que define genéricamente al ser humano como un sujeto histórico, a saber, la determinación de la vida humana como un proceso de metabolismo con su medio, cuya condición genérica brota de la forma concreta que toma materialmente dicho proceso a través del trabajo social y el desarrollo de las fuerzas productivas de este. A partir de este punto, el desarrollo avanza hasta reconocer la forma concreta que toma esta subjetividad genérica en las personas de la población objeto específico del estudio. Por lo tanto, en este desarrollo no se procede a través de la discontinuidad temática que bajo otros cursos metodológicos debe reconstituirse mediante el paso de una disciplina a otra (Marx, 1968: 153).

Si bien las determinaciones que exponemos han implicado e implican al conjunto de los pueblos indígenas del Chaco argentino, hacemos foco especialmente sobre sus alcances respecto de los qom de la porción oriental del Chaco central. Más específicamente aún, nos basamos de manera primordial en el trabajo etnográfico que hemos realizado en localidades rurales (y también periurbanas) del este de la provincia de Formosa desde 1999 hasta $2007^{3}$. En este sentido, nos referimos específicamente aquí a los qom de Misión Tacaaglé y de Potae Napocna Navogoh; ambas, comunidades rurales ubicadas sobre la ruta nacional № 86 , cercanas al río Pilcomayo y distantes, respectivamente, unos 195 y $137 \mathrm{~km}$ de la ciudad capital de Formosa (Iñigo Carrera, V., 2008, 2011, 2013 y 2014) (véase mapa). 
Mapa 1. Este de la provincia de Formosa, Chaco central, Argentina

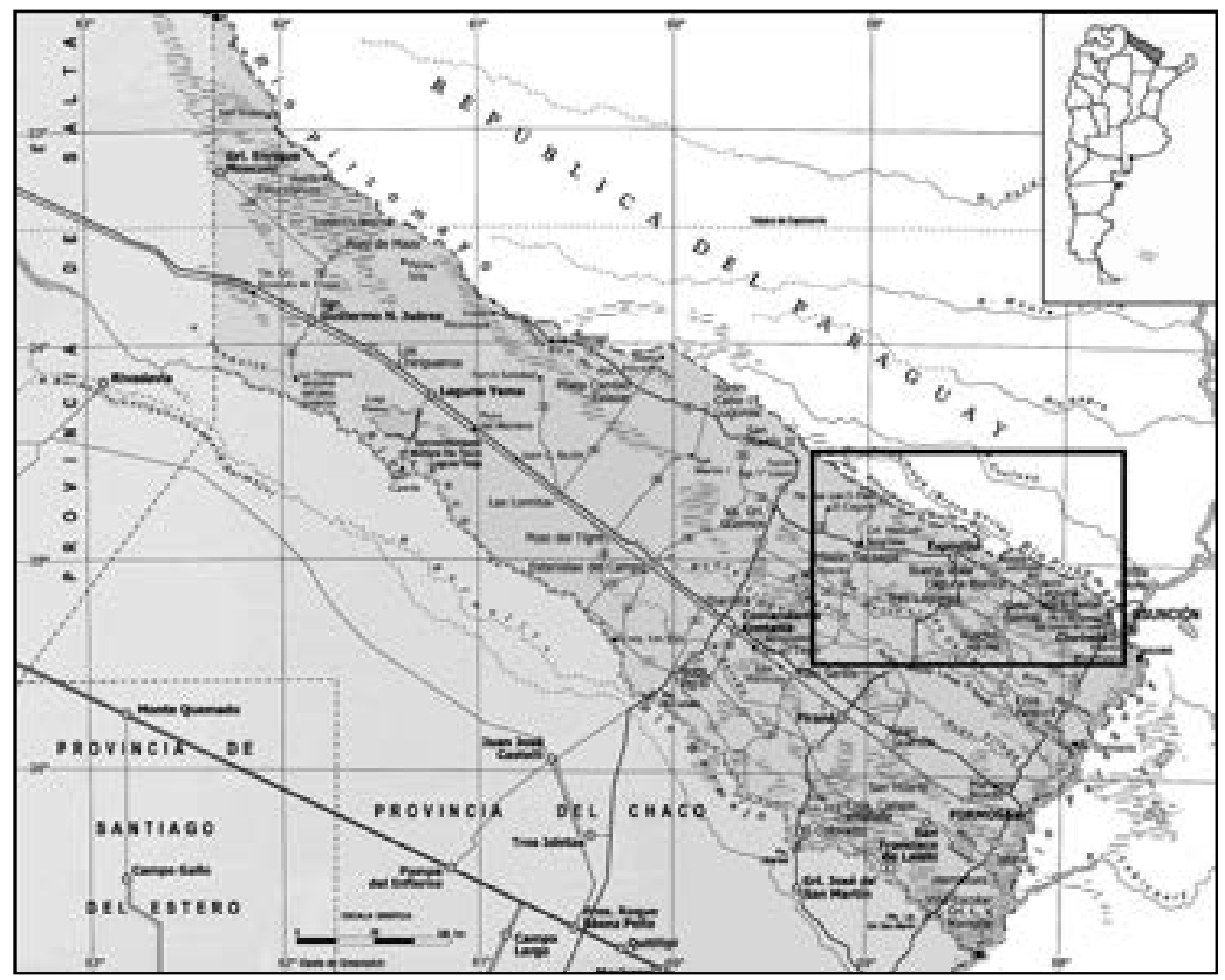

Fuente: Elaboración propia sobre la base de mapa del Instituto Geográfico Nacional.

2. La subjetividad genéricamente humana bajo su forma histórica capitalista

\subsection{La subjetividad que organiza su trabajo social de manera privada}

En su expresión más simple, la vida humana es un proceso de metabolismo del sujeto con su medio. Lo que distingue como genéricamente humano a este proceso es su realización a través de la acción consciente y voluntaria que opera sobre el medio para transformarlo en valores de uso; esto es, que se realiza mediante el trabajo (Marx, 1968). A su vez, la realización del trabajo tiene por condición la disposición por cada individuo de los medios de producción correspondientes. Pero no se trata de un simple proceso individual sino que se trata de un proceso de metabolismo social, donde los individuos trabajan para producir recíprocamente valores de uso unos para los otros. De modo que la unidad del proceso de metabolismo social se verifica en que el consumo del producto generado en un ciclo constituye la base material para la puesta en marcha de una nueva fase de producción. En consecuencia, el modo en que se asigna a 
cada individuo la porción concreta del trabajo social que va a ejecutar, es decir, el modo en que se organiza la producción social, rige asimismo la participación de cada quien en el consumo social de medios de producción y de vida. La conciencia es la forma en que cada individuo se reconoce como órgano del modo de reproducirse la vida social y, en consecuencia, la forma en que lleva en su persona la capacidad para regir su acción individual como tal órgano (Iñigo Carrera, J., 2007).

En los modos de producción anteriores al capitalista, el trabajo social concreto se le asignaba a cada individuo a través de distintos tipos de relaciones de dependencia personal. Estas relaciones presuponen la ligazón personal del trabajador con sus medios de producción. Pero el modo de producción capitalista disuelve violentamente los vínculos de dependencia personal a través de la realización privada del trabajo social (Marx, 1971). Esto es, en el momento que cada unidad privada de trabajo social se pone en marcha, lo hace sin haberse establecido la unidad de su producción respecto de la necesidad social por los valores de uso respectivos, o sea, con independencia respecto de las determinaciones del consumo de su producto. La unidad entre producción y consumo sociales recién se pone de manifiesto a posteriori, mediante la representación del gasto genérico de trabajo socialmente útil materializado de manera privada en sus productos, como el atributo de cambiabilidad de éstos, como su valor, determinándolos bajo la forma históricamente específica de mercancías (Marx, 2001). La producción de valores de uso para la vida humana se encuentra así mediada por la producción de valor, mientras que esta relación social general toma forma sustantivada en el dinero (lbíd.). Sobre esta base, la determinación misma de qué es una necesidad humana sufre un brutal desgarro: desde el punto de vista de la organización de la vida social sólo cuenta como necesidad aquella que es capaz de expresarse representada por el dinero. El hambre humano se diferencia entre hambre solvente, hacia el cual se orienta privadamente la producción social, y hambre insolvente, carente de vínculo social que le permita ser satisfecho (Iñigo Carrera, J., 2007).

La ausencia de vínculos de dependencia personal hace de los productores de mercancías individuos libres. Su interdependencia social respecto de las mercancías hace que las potencias genéricas de su trabajo social, o sea, de su acción consciente y voluntaria, se les presenten invertidas como potencias sociales que les son ajenas y los dominan. Para satisfacer sus necesidades de personas libres deben poner sus conciencias y voluntades al servicio de estas potencias sociales objetivadas, deben actuar como personificaciones de sus mercancías (Marx, 2001).

En su condición general de sujeto social, en el modo de producción capitalista cada individuo es indiferente respecto de las condiciones personales de los demás, con los cuales solo le cabe relacionarse de manera general como personificación. $Y$ las relaciones entre personificaciones tienen necesariamente el carácter antagónico que brota de expresar la forma privada del trabajo social; el interés individual de cada uno es contrario al de los demás a quienes se enfrenta directa o indirectamente en las relaciones de cambio: vendedor y comprador se enfrentan entre sí por la realización del valor de la mercancía y el dinero, vendedores por su lado y compradores por el suyo, en la competencia por quien impone el carácter 
social de su trabajo privado. En consecuencia, toda expresión directa de la unidad del proceso de metabolismo social se presenta como una confluencia que parte del antagonismo primario para desarrollar a este bajo la forma de relaciones de solidaridad. Es en su doble condición de sujetos libres por estar enajenados en las mercancías que las personas se constituyen como sujetos de las relaciones políticas de ciudadanía, es decir, como sujetos sociales en cuya acción consciente y voluntaria se encuentra portada la unidad del proceso de metabolismo social bajo la apariencia de que esta unidad brota de su sola conciencia y voluntad de ciudadanos recíprocamente independientes, que delegan su voluntad como tales en el estado (Iñigo Carrera, J., 2012).

El trabajo social realizado de manera privada presenta su expresión más pura bajo la condición de la propiedad privada sobre los propios medios de producción. Pero el modo de producción capitalista da un primer paso hacia la socialización del trabajo privado al tener en su origen histórico y reproducir continuamente, no sólo la disolución de los vínculos generales de dependencia personal, sino también la separación del productor directo, del trabajador, respecto de sus medios de producción. Determina así a quien trabaja como un individuo doblemente libre, que dispone privadamente de su fuerza de trabajo como única mercancía para vender y, en consecuencia, como única mercancía cuya venta le permite participar en el consumo del producto social. La capacidad genéricamente humana para realizar trabajo social se encuentra así determinada como un valor de uso materializado en el cuerpo del obrero. $Y$ no se trata de un valor de uso para su poseedor, que no la puede poner en acción por carecer de medios de producción (Marx, 2001).

\subsection{La inversión de la subjetividad produc- tiva humana como atributo del capital}

En su función como capital, el dinero no se limita a reconocer cuáles valores de uso son producto del trabajo social realizado privadamente. Como capital, el dinero actúa como un valor sustantivado que parte de reconocer como tal producto a los dos tipos de mercancías que constituyen la base material de la puesta en marcha de ese mismo trabajo social: la fuerza de trabajo y los medios de producción (Iñigo Carrera, J., 2013). Pone así en contacto a la fuerza de trabajo doblemente libre con sus medios de producción, de modo que aquélla actúa sobre éstos dando curso al proceso material de producción social de manera privada (Marx, 2001). Pero esta puesta en marcha del trabajo social no tiene por finalidad inmediata la producción de valores de uso para la vida humana, ni siquiera para el capitalista. Su finalidad inmediata es la valorización del capital, la producción de plusvalía. Desde el punto de vista del capital, el valor de uso de la fuerza de trabajo no reside en producir los medios para la vida humana, sino en producir más valor de lo que ella cuesta. No se trata de una producción de valores de uso sociales mediada por la producción de valor; se trata de la valorización del capital y sólo se producen valores de uso para la vida humana a condición de que se produzca plusvalía (Ibíd.). Se trata de un modo general de organizarse el proceso de metabolismo social, o sea de una relación social general, que tiene existencia sustantivada y se rige por la finalidad inmediata de reproducirse a sí misma. Por eso el capital se presenta bajo la apariencia enajenada de ser el sujeto concreto inmediato del proceso de vida social, y la vida humana invertida como un medio al servicio de ese sujeto (lbíd.). 
Esta inversión se refleja en la determinación misma de cuáles son los valores de uso necesarios para la reproducción normal de la vida natural de los trabajadores. El valor de la fuerza de trabajo está determinado por el valor de las mercancías que la familia obrera necesita consumir para proveer al capital de la fuerza de trabajo portadora de los atributos productivos que aquél requiere de ésta en cada momento y lugar de su proceso de valorización. La subsunción de los obreros en el capital no termina con la jornada de trabajo sino que, aun en el proceso de su consumo individual, y hasta en el proceso de su reproducción biológica, se encuentran determinados como atributos del capital. De ahí que la reproducción misma de la vida natural de la población obrera se encuentra subsumida en los avatares de la vida del capital concreto que valoriza con su trabajo (lbíd.).

Bajo esta subsunción, la producción agraria presenta dos condiciones que pueden darle una forma peculiar al proceso de reproducción de la fuerza de trabajo. Primero, el capital puede tener necesidad de fuerza de trabajo con carácter estacional. Segundo, fuera del período directo de trabajo para el capital, el obrero agrario puede producir sus alimentos básicos o alguna mercancía simple por su cuenta, a condición de disponer de los medios de producción elementales, incluido el acceso a la tierra, requeridos para ello. Sobre esta doble base, el capital agrario puede liberarse de absorber durante el período efectivo de trabajo el costo de la reproducción de la fuerza de trabajo por todo el año, dejando librado a la suerte de la producción por cuenta propia del obrero la satisfacción de una mayor o menor parte de esa reproducción. En este caso, el obrero agrario presenta la peculiaridad de ser un vendedor de fuerza de trabajo a la vez que un productor independiente de mercancías y un productor para autosubsistencia. Pero, por mucho que aparezca y se reconozca a sí mismo bajo la segunda figura, con el desarrollo del modo de producción capitalista ésta resulta plenamente determinada como forma peculiar de la primera, y no a la inversa. Es de su separación respecto de sus medios de producción generales que nace su condición de propietario privado de medios de producción específicamente limitados (Iñigo Carrera, N., 1984).

\subsection{La subjetividad política en que toma forma concreta necesaria la subjetividad productiva}

En el modo de producción capitalista, el antagonismo general entre compradores y vendedores de mercancías toma una forma específica en el inicio mismo de cada ciclo de la vida social. Se trata del antagonismo entre, en un polo, los vendedores de fuerza de trabajo y, en el otro, los compradores de fuerza de trabajo. A su vez, de este antagonismo primario surge la relación antagónica de competencia al interior de cada polo, de un lado, para dirimir quién como obrero logra vender individualmente su fuerza de trabajo y, del otro, para dirimir quién como capitalista logra individualmente comprarla. $Y$ este antagonismo secundario se resuelve a su vez en la relación de solidaridad al interior de cada polo que, en cuanto tiende a extenderse universalmente a ese interior, lo constituye como clase en relación antagónica con el otro polo. La unidad de la reproducción del proceso de metabolismo social toma así forma en la lucha general por la compraventa de la fuerza de trabajo entre la clase obrera y la clase capitalista, en la lucha de clases (Marx, 2001). 
La unidad de la reproducción del proceso de metabolismo social toma forma concreta como la unidad del movimiento del capital total de la sociedad a través de esta lucha que, por su mismo carácter, choca contra el movimiento fluido de dicha unidad. Luego este movimiento fluido toma a su vez forma concreta en una relación de solidaridad general que se presenta expresando la unidad de la reproducción del proceso de vida social como un interés común y general que aúna a obreros y capitalistas bajo la apariencia de tratarse de abstractos individuos recíprocamente libres e iguales como portadores de los mismos derechos y obligaciones. Tal es la relación política de ciudadanía del estado. Pero, así como el estado sigue presentándose como una relación social objetivada que parece brotar de la libre voluntad de esos individuos iguales en que éstos expresan su interés general, este interés general no tiene ya por contenido inmediato la producción de valores de uso regida por la producción de valor. Aquí, el contenido inmediato de la puesta en marcha del trabajo social es la producción de plusvalía en la unidad del movimiento del conjunto de los capitales de la sociedad, o sea, en la unidad del movimiento del capital total de la sociedad.

De modo que el estado expresa en su acción las necesidades de esta unidad en cada momento y lugar concreto, o en otras palabras, el estado actúa como el representante del capital total de la sociedad en el ámbito de las relaciones políticas (Iñigo Carrera, J., 2013).

En todas las formas de la relación social general desplegadas en el párrafo anterior, desde el simple contrato individual de trabajo hasta la unidad general del proceso de metabolismo social portada en la acción política, los individuos entran en su condición de personi- ficaciones. En este sentido, las condiciones y atributos de la subjetividad personal de cada uno resultan irrelevantes para el contenido en sí de la relación. Pero no ocurre lo mismo respecto de las formas concretas de realizarse ese contenido. En esta realización, las diferentes condiciones personales, aun las que aparecen originadas por vínculos personales preexistentes a la relación social general capitalista, se convierten en formas de ésta. Al hacerlo, dichas condiciones específicas propias de las subjetividades individuales actúan como potencias para el capital que las pone en acción. $Y$ lo hacen sin importar si su reproducción atenta contra la reproducción de la persona misma que las porta.

\subsection{El desarrollo del ser genérico humano bajo la forma histórica específica que priva de subjetividad productiva a una porción creciente de la humanidad}

La puesta en marcha del trabajo social regida por la valorización del capital se potencia mediante la producción de plusvalía relativa. Ésta se basa en el aumento de la productividad del trabajo, de modo de disminuir el valor de los medios de vida del obrero, disminuyendo con este la proporción de la jornada necesaria para la reproducción de la fuerza de trabajo, liberando así una mayor proporción de trabajo excedente. A su vez, el desarrollo sistemático de la maquinaria es la forma más potente de multiplicar la productividad del trabajo (Marx, 2001).

Ante todo, el desarrollo del sistema de la maquinaria revoluciona la materialidad del trabajo. Éste va dejando de consistir esencial- 
mente en la aplicación consciente de la fuerza y pericia humanas sobre la herramienta, para hacer que ésta actúe sobre un objeto, transformando así el valor de uso del mismo. En cambio, va tendiendo a consistir en la aplicación del gasto consciente de cuerpo humano al ejercicio del control científico sobre las fuerzas naturales, y a la objetivación de este control como un atributo de la maquinaria, de modo de descargar automáticamente dichas fuerzas naturales sobre la herramienta, haciendo que ésta actúe transformando el valor de uso del objeto del trabajo (Iñigo Carrera, J., 2013). Estas transformaciones en la materialidad del trabajo tienen un doble efecto contrapuesto sobre los atributos de los obreros que entran en producción. Por una parte, el capital desarrolla la subjetividad productiva de la porción de la clase obrera que participa en el desarrollo de la capacidad para avanzar en el control universal de las fuerzas naturales y en el control consciente del propio carácter colectivo del trabajo (Iñigo Carrera, J., 2013). Por la otra, el sistema de la maquinaria convierte al obrero que aplica su pericia manual en el proceso directo de producción en un apéndice de la maquinaria o en un órgano cada vez más parcializado de la división manufacturera del trabajo, degradando así su subjetividad productiva. Su trabajo se ve constantemente descalificado, despojado de todo contenido más allá de la repetición mecánica de una tarea cada vez más simple (Marx, 2001).

Pero el sistema de la maquinaria tiene un tercer efecto aún más brutal sobre la subjetividad productiva del obrero. Con cada avance en el desarrollo de la maquinaria, el capital reemplaza la intervención de la subjetividad habilidosa del obrero en el proceso de producción por la tecnología objetivada en la máquina. Bajo su forma capitalista, este desarrollo de las fuer- zas productivas del trabajo social no se traduce en el alivio de trabajo para la población obrera. Por el contrario, se traduce en la transformación de masas crecientes de población obrera en sobrante para las necesidades de explotación del capital (lbíd.).

Como el capital es el vínculo social general que organiza la vida natural de la propia población obrera, el ser relativamente sobrante para el capital es serlo para la vida natural misma. El capital impone primero a la superpoblación obrera la venta de su fuerza de trabajo por debajo del valor, de modo que esta superpoblación no puede ya reproducirse en condiciones normales. Con lo cual, el capital empieza por arrancarle el ejercicio de su capacidad para trabajar, y continúa avanzando hasta impedirle directamente a la población que convierte en sobrante el desarrollo de su capacidad para trabajar, esto es, hasta arrancársela directamente. Al comenzar, resaltamos que esta capacidad es la que determina al género humano como tal. Por lo tanto, cuando la superpoblación obrera lucha en defensa de su participación en el proceso de producción social, está luchando por la afirmación de su condición genéricamente humana, es decir, por su dignidad de ser humano.

Para la población trabajadora rural, incluyendo los pequeños productores propietarios de sus medios de producción, el desarrollo de la producción de plusvalía relativa basada en el desarrollo de la maquinaria tiene un doble efecto que acentúa específicamente las determinaciones recién vistas. Los obreros de los centros urbanos se encuentran inmersos en la diversidad de las ramas de actividad localizadas en éstos. Esta diversidad los produce con ciertos atributos generales que, cuando son desplazados de la producción por la incor- 
poración de la maquinaria en una rama, dan base a la posibilidad de salir de la condición de sobrantes vendiendo su fuerza de trabajo en otra. La misma diversidad de actividades propia de los centros urbanos opera en este mismo sentido. En cambio, el obrero rural solo cuenta con la actividad específicamente agraria para el desarrollo de sus atributos productivos. A su vez, desplazado de esta actividad por el desarrollo de la maquinaria, no encuentra en su medio rural otra rama de actividad a la cual concurrir para intentar vender nuevamente su fuerza de trabajo.

Queda entonces retenido en su lugar de origen bajo la condición de una superpoblación obrera en estado latente hasta que el capital la atrae con fuerza suficiente hacia alguna rama localizada en otro ámbito espacial, en particular en los centros urbanos (Ibíd.). Por su parte, los pequeños productores rurales independientes también desplazados por el desarrollo de la maquinaria a la cual no tienen acceso, cuentan con la posibilidad de extender su permanencia en esa situación de latencia antes de migrar para encontrar comprador potencial para su fuerza de trabajo, llevando sus condiciones de producción agraria al extremo de agotar absolutamente la vida útil de sus instrumentos de producción sin siquiera obtener para sí, al mismo tiempo, el equivalente a un salario. $Y$ la posibilidad de subsistencia en el ámbito rural se extiende todavía más cuando cabe recurrir a la autoproducción de medios de vida, o a convertirse en un vendedor ocasional de fuerza de trabajo.

Sin embargo, cuando la capital de los centros urbanos tienen saturada su necesidad de superpoblación obrera a su disposición directa, los obreros y los productores rurales desplazados por la maquinaria dejan de constituir para dicho capital una fuente latente de fuerza de trabajo. Se levantan entonces barreras que se tornan infranqueables para la población sobrante rural, que pasan a consolidarse abiertamente en condiciones de pauperismo agudo en el mismo medio rural de origen.

\section{Trabajadores indígenas en el Chaco argen- tino: de propietarios de sus condiciones de trabajo a población obrera sobrante}

\subsection{Despojo del productor directo indígena de sus condiciones de trabajo: un trabajador productivo para el capital}

En el marco de las formas que precedieron a la producción capitalista en el Chaco argentino, los trabajadores indígenas se comportaban con las condiciones objetivas de su trabajo como con su propiedad, con la tierra -en tanto principal condición natural de producción- como con su laboratorium natural (Marx, 1999). En tanto objeto y medio de trabajo, la tierra los surtía de medios de vida susceptibles de ser consumidos de manera directa, de modo que el trabajo humano se limitaba a desprenderlos de su contacto directo con la naturaleza (Marx, 2001). Las actividades de caza, pesca, recolección de frutos silvestres y miel y, en menor medida, una agricultura de roza incipiente, constituían la particular objetivación de la apropiación de las condiciones materiales de su vida. Se trataba de actividades productivas que implicaban poco cambio de forma de los objetos apropiados (frutos del suelo), en tanto era limitado el alcance de las fuerzas productivas de la sociedad. Lo era aun en aquellas actividades que suponían un mayor grado de desarrollo de esas fuerzas: las técnicas de la agricultura, por caso, eran simples en comparación con las de otros 
pueblos indígenas. Claro está que, dentro del limitado desarrollo de las fuerzas productivas del trabajo, las distintas actividades productivas ya requerían el desarrollo de ciertas aptitudes o capacidades por parte del individuo que las realizaba. En esta forma de relacionarse con el medio, "los individuos no se comportan como trabajadores sino como propietarios -y miembros de una entidad comunitaria, que al mismo tiempo trabajan" (Marx, 1999: 68). El objeto inmediato de su trabajo, de su apropiación de la naturaleza, era su propia reproducción, la de su familia y la de la entidad comunitaria de la que formaban parte; apareciendo esta última como condición de la apropiación colectiva del suelo y de su utilización. En otras palabras, la organización general del trabajo social se regía sobre la base de relaciones de dependencia personal: era en cuanto miembro de la comunidad que un individuo determinado tenía un lugar en la producción y en el consumo sociales ${ }^{4}$.

Ahora bien, lo que necesita ser explicado, no es la unidad del individuo con las condiciones inorgánicas de su existencia, esto es, su apropiación de la naturaleza, sino la separación entre dichas condiciones y dicha existencia, una separación que cristaliza en la relación entre trabajo asalariado y capital (Marx, 1999). Ante todo, esta separación implicó la transformación de los productores directos indígenas en vendedores de fuerza de trabajo.

En este sentido, se vieron lanzados al proceso de ser constituidos en individuos portadores de la doble libertad propia del trabajador asalariado, que mencionamos anteriormente (lbíd.) Tal como es propio de la generalidad del proceso de acumulación originaria del capital, la separación de las condiciones materiales de existencia -que encontraría una de sus expresiones en la limitación de su acceso a los ríos y en la reducción de sus campos de caza como consecuencia de la progresiva ocupación privada de las tierras en las que desarrollaban sus actividades de subsistencia- fue a través de la aplicación de una coacción física directa. Por cierto, como parte del proceso de avance del capital, se sucedieron las campañas militares. Iniciado de manera esporádica, aproximadamente a mediados del siglo XVI, hacia los límites occidental, oriental y austral de la región, el envío de expediciones militares encontró su punto culminante -aunque no definitivo- en la campaña de 1884 al Chaco austral y a los extremos sur y oriental del Chaco central.

\subsection{Obrajes, ingenios y plantaciones}

Separadas, de manera repentina y violenta, de aquellas condiciones, masas de brazos indígenas fueron absorbidas por distintas expresiones del avance del capital -en cuyo desarrollo mucho tuvieron que ver las aptitudes agronómicas del suelo y las características climáticas propias de cada porción del Chaco-: los obrajes madereros, los ingenios azucareros y las plantaciones algodoneras.

Si bien la existencia de obrajes para la extracción de palmas y algarrobos sobre la ribera del río Paraguay se remontaba, incluso, al siglo XVII, fue desde mediados del siglo XIX y hasta la década del treinta del siglo XX que se establecieron obrajes madereros y aserraderos para la fabricación y comercialización de postes de quebracho colorado para el alambrado de los campos y de durmientes para el tendido de las vías del ferrocarril, así como para la obtención de carbón vegetal para los ferrocarriles y los trapiches del azúcar de las provincias de Tucu- 
mán, Salta y Jujuy y de tanino para las curtiembres. De manera temprana, fueron objeto de la explotación los extensos bosques de maderas duras y semiduras del norte de Santa Fe, del este de Chaco -sobre la costa del río Paranáy del noreste de Santiago del Estero. En el año 1881, el gobierno santafesino otorgó a La Forestal S.A. (la mayor empresa capitalista de la industria forestal) 1.804 .563 hectáreas. Esta compañía inglesa llegó a tener cuatro fábricas de tanino en Santa Fe (cerradas entre 1948 y 1963), empleando unos 40.000 trabajadores (Trinchero, 2000). No obstante la importancia de la producción de tanino para la economía del Territorio Nacional de Formosa, la participación formoseña en la totalidad de la producción nacional -llevada adelante en establecimientos de baja inversión tecnológica y productividadfue marginal, alcanzando hacia 1930 no más del 10\% del total nacional (Slutzky, 1975).

Por su parte, el cultivo de la caña de azúcar constituía, ya a mediados del siglo XIX, la actividad económica más importante del valle de San Francisco (ubicado en las últimas estribaciones orientales de los Andes, en las puertas del Chaco). Se trataba de una producción realizada con técnicas muy rudimentarias, que encontró su despegue en 1870 a partir de la transformación de las haciendas azucareras en ingenios que se consolidaron como complejos compuestos por plantaciones y fábricas bajo la administración de una empresa centralizada (Gordillo, 1995). Mucho aportó a este despegue la promoción operada desde el Estado a través de las exenciones impositivas a la importación de maquinaria, el apoyo crediticio y la protección arancelaria específica (Campi y Bravo, 1999). Los de mayor importancia serían los saltojujeños: San Martín del Tabacal, San Isidro, Ledesma, La Esperanza, San Pedro, La
Mendieta y Río Grande; a ellos se sumaron los ingenios azucareros del Chaco oriental: Reconquista, Avellaneda y Villa Ocampo (en el norte de Santa Fe), Resistencia y Las Palmas (en el este de Chaco) y La Teutonia y Santa Elena (en el este de Formosa). De poca tecnificación y con un volumen de producción menor a los ingenios de Salta y Jujuy, la producción de estas dos últimas fábricas -instaladas a fines de la década de 1880 y cuya permanencia apenas superaría la entrada del nuevo siglo- sería solo un apéndice de la nacional (Borrini, 1987; Prieto, 1990).

Por último, fue hacia comienzos de la década de 1920 que, tras una crisis de la producción algodonera internacional que coadyuvó a su rápido desarrollo, se abrió paso de manera decidida la producción agrícola centrada en el cultivo del algodón -cuyo desarrollo incipiente databa del siglo anterior-, siendo Chaco la provincia que históricamente y por lejos ha aportado el mayor porcentaje a la producción total nacional. Este desarrollo -en principio, en el marco de una demanda externa favorable y, luego, como consecuencia de una demanda interna en expansión- fue fuertemente impulsado por el Estado a través del financiamiento, la asistencia técnica, la comercialización y la instalación de desmotadoras oficiales y de escuelas de clasificadores del textil (Guy, 2000). Desde sus inicios, se trató de una producción realizada en unidades productivas pequeñas y medianas, con una importante participación de trabajo familiar. Esto fue más significativamente así en la provincia de Formosa (Gordillo, 1995).

En síntesis, podemos identificar varios frentes, con distintos grados de capitalización y gravitación regional, para una misma expansión: la del capital. Todos ellos, esto es, los 
obrajes madereros, los ingenios azucareros y las plantaciones algodoneras, tuvieron un elemento en común: el requerimiento de mano de obra en forma intensiva en determinados momentos de sus respectivos procesos productivos (la madera, cuando el árbol se encuentra en latencia y la temperatura permite hachar; el azúcar y el algodón, en el momento de la preparación del suelo y de la cosecha) (Iñigo Carrera, N., 1988). Con el propósito de satisfacer esa demanda de mano de obra estacional se procedió, en todos los casos, al reclutamiento de indígenas. $\mathrm{O}$, lo que es lo mismo, el desarrollo de los distintos sistemas productivos en la región tenía por condición de posibilidad no sólo la apropiación privada individual de la tierra y los recursos en ella contenidos, sino también la disponibilidad de mano de obra indígena. Con la incorporación de los pueblos indígenas al trabajo en los obrajes, ingenios y chacras, el modo capitalista se impuso -ahora sí, de manera definitiva- como la forma social general del proceso de producción, transformando toda forma social anterior a él en una forma concreta suya, que operó y opera para la valorización del capital.

\subsection{Absorción y expulsión de los qom de la producción de algodón en Formosa}

De entre las formas que tomó el avance del capital en el Chaco argentino, el cultivo del algodón fue el que, desde que inició su ciclo sostenido de expansión en la década de 1920, absorbió en mayor proporción la masa de brazos indígenas de la porción oriental del Chaco central (Bartolomé, 1972; Gordillo, 2004) ${ }^{6}$. Por su parte, los qom, wichí, chorote, pilagá, tapiete, nivaclé, chané y guaraníes del Chaco centro-occidental fueron mayormente incorporados a la fuerza de trabajo de los ingenios saltojujeños para las tareas de corte, pelado, carga y acarreo de la caña ${ }^{7}$. La incorporación de los qom a la producción algodonera en Formosa fue como trabajadores asalariados de temporada en las labores de carpida (desmalezamiento) y cosecha del cultivo, y como pequeños productores independientes de algodón en bruto.

La escala de la producción algodonera se ha caracterizado históricamente por fuertes oscilaciones de una campaña agrícola a otra, y también han transcurrido momentos de fuerte expansión intercalados con otros de igualmente fuerte contracción de carácter generalizado. Pero por sobre estos movimientos circunstanciales se manifiestan ciertas tendencias que resultan centrales para la cuestión planteada.

Cuando el algodón inició su ciclo sostenido de expansión, Formosa se afirmó como segunda provincia productora, detrás de Chaco. En la década de 1970 la producción formoseña alcanzó su pico histórico, llegando a representar el $16 \%$ del total nacional. Pero a partir de entonces su escala entró en un proceso de continua contracción. Esta contracción contrasta con la sostenida expansión de la producción algodonera en el resto del territorio argentino, que continuó hasta alcanzar su propio pico en la década de 1990; y aunque retrocedió durante la década siguiente, en la primera mitad de la década actual recuperó dicho nivel pico. Para este último período, la producción de Formosa representó menos del 3\% de la producción nacional. Surge entonces la pregunta acerca de las determinaciones particulares que operan en la producción algodonera en Formosa, que la hacen seguir un curso contrapuesto al dominante en el resto del territorio nacional dedicado a este cultivo, pese a no presentar condiciones 
agroecológicas sustancialmente diferentes a las de este.

La primera determinación en este sentido lo constituye el cambio en las condiciones técnicas de la producción de algodón, a partir de la década de 1980, mediante la sustitución de la carpida manual por el control químico y mecánico de las malezas, y de la cosecha manual por la mecánica. La expresión más contundente del incremento de la productividad del trabajo algodonero ha sido el salto originado por la mecanización de la cosecha. Mientras un cosechero promedio (varones, mujeres y niños) recoge $80 \mathrm{~kg}$ diarios de algodón si realiza su trabajo en forma manual, a principio de la década de 1990 se alcanzaban los $6.000 \mathrm{~kg}$ por operario utilizando una cosechadora de dos surcos, a razón de dos operarios por máquina (Basterra, 1991). Además, la incorporación de la cosechadora acortó el período de tiempo insumido por la cosecha. Según datos de la Estación Experimental Agropecuaria de Sáenz Peña del Instituto Nacional de Tecnología Agropecuaria, ya en dicha década la mecanización se expandió, alcanzando más del $80 \%$ de la superficie algodonera total del país. Esta expansión se vio favorecida por la disminución en el precio de las cosechadoras importadas y de los agroquímicos usados para acondicionar el cultivo a ser recolectado de forma mecánica, y por una modificación en el régimen impositivo.

La cosecha manual solo podría haber competido con la productividad del trabajo mecanizado y las condiciones que favorecían adicionalmente la incorporación de la maquinaria sobre la base de la disminución aguda del salario de los cosecheros. Pero esta posibilidad se encontraba agotada desde antes, porque dichos salarios ya se ubicaban por debajo de los niveles mínimos de subsistencia, al punto de que la cosecha manual se sostenía en el uso masivo del trabajo infantil (Iñigo Carrera, J., 2008).

Para acceder a los crecientes beneficios que supuso la utilización de la opción mecanizada se requería disponer del capital adicional aplicado a la incorporación de la maquinaria. En consecuencia, la producción algodonera pasó por un proceso acelerado de concentración y centralización del capital, el cual a su vez se expresó en la creciente diferenciación entre los agentes de la producción. Aquí es donde se hace manifiesta la evolución peculiar de la producción algodonera en Formosa.

El cultivo del algodón en Formosa ha estado históricamente en manos de una multiplicidad de pequeños productores con, en principio, una tenencia precaria de la tierra y escasas, sino nulas, posibilidades de acumulación; entre ellos, los qom. No solo carecen del capital necesario para adquirir la cosechadora, sino que su uso sobre terrenos de poca extensión encuentra barreras técnicas que lo hacen rentable únicamente a partir de cierta extensión de los predios. De este modo, a la vez que fueron testigos de la promoción del capital agrario concentrado, el decenio de 1990 encontró a la supervivencia de la pequeña explotación, más que nunca, en jaque. Imposibilitados de incorporar la maquinaria y de incrementar su escala, los agentes de menor tamaño se vieron expulsados de manera inmediata de la producción o, cuando menos, se mantuvieron en actividad a expensas de reducir la superficie sembrada con algodón. Así, los Censos Nacionales Agropecuarios de 1988 y 2002 muestran una disminución en el número de explotaciones algodoneras y un decrecimiento en el tamaño medio del predio algodonero (a excepción, esto último, 
del estrato que aglutina las explotaciones de mayor superficie, que evidencia una tendencia en sentido contrario) ${ }^{8}$.

En la unidad de las determinaciones expuestas, la introducción de la mecanización del laboreo y la cosecha ha encontrado en Formosa una barrera particular. Si bien esta barrera ha significado un freno a la disminución en la demanda de fuerza de trabajo estacional, es innegable también que la inviabilidad de aquella introducción ha redundado en la dificultad de las pequeñas unidades para mantenerse en producción. Lo cual ha determinado la tendencia decreciente en la escala de la producción algodonera formoseña señalada anteriormente y, de manera consecuente, en dicha demanda. La magnitud de este decrecimiento se puede estimar considerando que, sobre la base del trabajo de carpida y cosecha manual, la producción provincial requería alrededor de 14.000 jornadas de trabajo estacional en equivalentes/hombre por siete meses en la década de 1970, 11.000 en la de 1980, 6.000 en la de 1990, 5.000 en la de 2000 y 3.000 en la primera mitad de la de 2010 (sobre la base de Iñigo Carrera, V., 2008). La disminución es incluso más aguda, ya que, pese a las barreras señaladas, la incorporación de la cosecha mecánica ha avanzado significativamente, duplicándose la superficie cubierta por ella entre los censos de 1988 y 2002, en contraste con la reducción de la superficie total.

El conjunto de estas determinaciones no ha hecho sino generar la progresiva mutilación de los atributos productivos de la fuerza de trabajo indígena. Más aún, en un escenario en que son motores primordiales de la forma de acumulación de capital en el espacio del agro chaqueño: la difusión del cultivo de la soja (producto de las condiciones climáticas, la nueva tecnología y el precio de la oleaginosa $)^{9}$, la apropiación de la tierra a un precio por debajo del correspondiente al flujo futuro de renta capitalizada, la propagación de capitales concentrados (muchos de ellos, extra-regionales), la inversión en infraestructura fija a gran escala. Se trata de una mutilación que encuentra múltiples expresiones; a continuación, desplegamos aquéllas que atañen a los qom de Misión Tacaaglé y de Potae Napocna Navogoh.

\subsection{Los qom de Misión Tacaaglé y Potae Napocna Navogoh: su (re)producción como una población obrera sobrante}

Los qom de Misión Tacaaglé y Potae Napocna Navogoh son dueños de las tierras que ocupan, bajo la forma de sendos títulos comunitarios ${ }^{10}$. Las unidades domésticas (de residencia, producción y consumo) que hoy conforman ambas comunidades las dedican a la producción de algodón como principal, si no único, cultivo comercial. Lo hacen en una superficie que no supera, en promedio, las dos hectáreas. Se trata de una producción para la cual requieren que el Instituto de Comunidades Aborígenes (agencia provincial para la administración de los asuntos indígenas) les prepare el suelo -a través de la contratación del servicio a terceros o a los municipios locales- y les provea las semillas necesarias. Los insumos utilizados (herbicidas, insecticidas, regulador de crecimiento) son suministrados por el Ministerio de la Producción y Ambiente de la provincia. La asistencia tiene lugar a través de la instrumentación del Programa Agrícola de Asistencia a Pequeños Productores Aborígenes, en su componente algodón. Sin embargo, su incidencia es mínima: en el año agrícola 
2005/2006, representaba un área de cultivo de apenas 1.100 ha. de algodón en la totalidad de las comunidades indígenas de la provincia, de las cuales 75 correspondían a Potae Napocna Navogoh y 50 a Misión Tacaaglé. Por su parte, realizan aquella producción con la utilización de herramientas precarias, deterioradas y de tracción animal, sin posibilidad de reponer sus instrumentos de producción una vez que han agotado su vida útil. El trabajo en las labores culturales y de cosecha es el fruto de la familia extensa, un grupo de parientes que cooperan en la puesta en producción de la chacra y comparten recursos. En ocasiones, se emplea fuerza de trabajo ajena para levantar la cosecha, reclutada entre los miembros de otras unidades domésticas a través del despliegue de una serie de prestaciones y contraprestaciones en trabajo en las que su organización no es objeto de una relación salarial. La venta del algodón en bruto suele ser al pequeño acopiador privado local (bolichero) que se acerca a las comunidades y que, como primer eslabón del circuito de comercialización, paga precios más bajos por esa mercancía. Son pocos quienes alcanzan a comercializar el textil en la planchada de acopio habilitada por el Estado provincial ${ }^{11}$.

Pero la falta de herramientas e insumos para poner la tierra en producción a menudo resulta en el arrendamiento de sus parcelas a "blancos del pueblo"12, ya sea para el pastaje de animales o para cultivo; se trata de agentes externos de la producción con claros vínculos con la estructura de poder local. Fueron éstos -y no los qom- quienes tuvieron en sus manos la multiplicación de la superficie sembrada con algodón en Tacaaglé hasta llegar a las 177 ha. en el año agrícola 2003/2004 -tras la estrepitosa caída registrada en 1999/2000 en que arañó las 30 ha.- Tras su arrendamiento, es frecuente la asalarización de los qom como carpidores y cosecheros en sus propias tierras. También lo es el trabajo asalariado en predios vecinos correspondientes a capitales de mayor monto y en tareas de carpida y cosecha de diversos cultivos. No obstante, los salarios obtenidos apenas alcanzan para su reproducción física durante el período de trabajo. Al trabajo asalariado y la producción agrícola mercantil se le agrega la práctica de una agricultura dirigida al propio consumo, que suele restringirse a media hectárea de tierra. Es el Instituto de Comunidades Aborígenes, a través del mencionado Programa Agrícola en su componente autoconsumo, el organismo que brinda la asistencia necesaria a través de la entrega de semillas (sandía, calabacita, melón, zapallo, maíz, hortalizas). El mismo instituto entrega medios de vida (harina, azúcar, yerba, sal, grasa, denominados genéricamente como "mercaderías") para el sostenimiento inmediato de las familias durante el período de ocupación en las tareas agrícolas. Dos son, hasta aquí, las maneras en que el Estado interviene en la reproducción social de la vida de los qom. Una, la promoción de actividades destinadas a la producción de mercancías que entren en el consumo social general (algodón) $^{13}$ y el impulso de otras actividades productivas destinadas al consumo individual de quienes intervienen inmediatamente en ellas y el de la comunidad en su conjunto (huertas). No obstante, la manera predominante es la constitución generalizada de los qom en beneficiarios de programas sociales de asistencia a la pobreza y al desempleo, mediante ayudas económicas no remunerativas, asistencia alimentaria directa, pensiones asistenciales no contributivas, becas de estudio, medicamentos. Por ejemplo, en 2004, a 
nivel provincial, los beneficiarios promedio por mes de programas sociales de empleo, nacionales y provinciales, eran unos 51.477 , registrándose una cobertura del $18 \%$ de la población mayor de dieciocho años. El nivel de cobertura del Programa Jefes y Jefas de Hogar Desocupados -creado en 2002, tras declararse el "estado de emergencia ocupacional nacional" (Decreto № 165), con el objeto de brindar una ayuda económica no remunerativa mensual a los jefes de hogar desocupados- era el más alto en todo el país (Dirección de Análisis de Gasto Público y Programas Sociales, 2009). Las magnitudes, ya de por sí elevadas, se tornaban dramáticas entre los qom. Que el Estado intervenga en la reproducción de los qom, y de manera fundamental, bajo esta última forma -una que encuentra diluida, cuanto menos, su asociación con la promoción de la actividad laboral productiva- no hace sino hablar de la progresiva mutilación de los atributos productivos de esta fuerza de trabajo indígena.

\section{Conclusión}

En apenas un siglo, la historia de los qom de la porción oriental del Chaco central constituye una síntesis acabada de una determinación concreta específica del modo de producción capitalista. Ella pone de manifiesto de manera brutal la inversión de la subjetividad humana como atributo del capital. A fines del siglo XIX, la expansión del capital sobre el Chaco argentino tomó la forma clásica de un proceso de acumulación originaria consistente en separar a los pueblos indígenas de sus condiciones materiales de vida, principalmente la caza y la recolección. Esta expropiación tuvo lugar mediante la violencia armada que literalmente los "redujo" encerrándolos en espacios cercados (Iñigo Carrera, N., 1984). El avance del capital ya veía en dichos pueblos una fuente de fuerza de trabajo apropiada para, primero, la explotación maderera del bosque nativo y, hecho el desmonte, para el cultivo y la cosecha del algodón, y para la zafra azucarera. En un momento histórico general que ya chocaba con la utilización de fuerza de trabajo esclava, se los transformó en obreros asalariados, palos y evangelización mediante.

Pero esta transformación distó de implicar su transformación plena en sujetos productivos doblemente libres: al mismo tiempo que abarató su fuerza de trabajo estacional para el capital al transformarlos parcialmente en pequeños productores independientes, les mutiló su subjetividad política de individuos libres al negarles la condición plena de ciudadanos del estado nacional hasta mediados del siglo XX. Así como en la década de 1880 alcanzó su punto culminante la campaña militar que abrió esta transformación de la subjetividad productiva de los qom en fuerza de trabajo para el capital, en la década de 1980 se abrió el proceso que viene socavando sus posibilidades de ejercer dicha subjetividad. En esa década, la introducción del laboreo y la cosecha mecánicos en el cultivo del algodón, con su consiguiente efecto sobre el proceso de concentración y centralización del capital, dio paso a la renovada violencia de verse crecientemente privados de participar en el proceso de producción algodonera. Los qom alcanzados por este efecto pasaron entonces, de la condición de sujetos simplemente activos del proceso de trabajo, primero a la condición de superpoblación obrera relativa retenida en su lugar de origen en estado latente para el capital. En estas condiciones, sólo podrían encon- 
trar nuevos compradores para su fuerza de trabajo migrando a otras áreas rurales o, principalmente a los centros urbanos. Aun esta posibilidad se ha visto estrangulada por la marcha general del proceso nacional de acumulación de capital. De modo que los trabajadores qom afectados van quedando retenidos en el espacio rural originario, pero ya no en la condición latente anterior sino en la de una superpoblación obrera relativa -ya que prácticamente carecen de alternativas productivas por cuenta propia, de modo que sólo les queda su fuerza de trabajo como mercancía para vender- que se va consolidando en la condición de tal.

El capital les va arrancando así, primero, el ejercicio de su capacidad para trabajar y, luego, avanza arrancándoles hasta esta capacidad misma. Con lo cual los empuja al pauperismo agudo, pudiendo reproducirse precariamente sobre la base de constituirse de manera generalizada en beneficiarios de programas sociales de asistencia a la pobreza y al desempleo.
Privados en un grado significativo de su subjetividad productiva, deben recurrir a la forma de su subjetividad política como medio para participar en el consumo social a través de la acción reivindicativa en demanda de dichos programas, donde la condición de indígena opera de manera específica y -en un proceso en el cual el capital les degrada aun su subjetividad políticalas relaciones clientelares.

Como señalamos al comienzo, el ser humano es genéricamente un sujeto histórico porque cada generación entrega a la siguiente un mundo que ha sido producido por su trabajo. Nada más falso, entonces, que la concepción de los qom como un "pueblo sin historia" en su origen, rescatado de esta condición por el avance del capital. Muy por el contrario, es el modo de producción capitalista mismo el que priva a los qom del ejercicio de su condición genéricamente humana de sujetos históricos al privarlos del ejercicio de su condición genéricamente humana de sujetos productivos. 


\section{Notas}

1 El Chaco argentino constituye una extensa llanura que abarca una superficie de unos $400.000 \mathrm{~km}$ y que tiene por límites, al norte, el río Pilcomayo, al este, los ríos Paraná y Paraguay, al oeste, las últimas estribaciones de las sierras subandinas, y al sur, el río Salado y el pie de las sierras de Córdoba. El río Bermejo divide a la región en dos grandes subregiones: el Chaco austral al sur (entre los ríos Bermejo y Salado) y el Chaco central al norte (entre los ríos Bermejo y Pilcomayo). Desde el punto de vista político, mientras que al Chaco austral le corresponde la actual provincia de Chaco, el norte de Santa Fe y el noreste de Santiago del Estero, el Chaco central involucra la totalidad de la provincia de Formosa y el noreste de Salta (más adelante se incluye mapa de la región con indicación del área específica sobre la que se centra el presente trabajo).

2 Son numerosos los pueblos indígenas que habitan el Chaco argentino en su conjunto: qom, mocoví y pilagá (de la familia lingüística guaycurú); wichí, chorote y nivaclé (de la familia lingüística mataco-mataguayo); guaraní, chané y tapiete (de la familia lingüística tupí-guaraní) (Gordillo y Hirsch, 2010).

3 Un gran número de estudios antropológicos sobre los qom del este del Chaco central estructura sus argumentaciones en torno a las percepciones, nociones, versiones e interpretaciones de la realidad elaboradas por los propios sujetos. Por cierto, el imperativo autoimpuesto de recuperar la "perspectiva del nativo" ha sido históricamente parte del programa de la construcción de conocimiento antropológico. La aproximación etnográfica se ha referido así a una forma de acceder al nivel de las prácticas de los sujetos, presentándolas en los términos de su propia voz, la cual se revelaría transparente y, en tanto tal, objetiva y verdadera. Lejos de negar la posibilidad, e incluso necesidad, de una perspectiva centrada en los sujetos que haga foco en la producción de sentidos, el análisis no debe detenerse simplemente en la "verdad" narrada por aquél (Menéndez, 2002). Sobre estas bases, el trabajo realizado en terreno se fundó en una metodología que, a la par de coadyuvar al conocimiento de la experiencia cotidiana y localizada de los sujetos sociales, permitiera avanzar asimismo sobre sus determinaciones. Para ello, el diseño metodológico contempló, entre otras situaciones, aquellas relacionadas con la observación y/o participación y registro de las prácticas y sentidos desplegados por los distintos sujetos, así como aquellas otras vinculadas al relevamiento, procesamiento y análisis de información proveniente de registros estadísticos y documentales.

${ }^{4}$ El trabajo es siempre un gasto individual de cuerpo humano, pero sus potencias productivas no brotan simplemente de la individualidad inmediata del trabajador, sino que esta individualidad es la forma en que se realizan las potencias productivas sociales. Esto es en dos sentidos. Por un lado, la potencia productiva de un individuo depende de la actividad productiva del conjunto social. Por otro lado, la potencia productiva de un individuo depende de que realice su trabajo cooperando directamente con otros, es decir, como órgano individual de un trabajo directamente colectivo, de un obrero colectivo, social (Iñigo Carrera, J., 2008).

${ }^{5}$ Con respecto a estos sentidos, es conveniente señalar que se preserva la propiedad para el productor directo sobre medios de producción limitados, que no permiten ya la producción sobre la base material anterior, así como se mantiene cierto grado de relaciones personales directas entre dichos productores sobre la base de su condición de indígenas.

6 En tanto, Cordeu y Siffredi (1971) y Miller (1979) reseñaron la importancia de la agroindustria del algodón para los qom de la provincia de Chaco (en términos regionales, el Chaco austral).

7 Esto fue así hasta que en la década de 1960 se produjera una mayor tecnificación de los procesos de trabajo (alcanzando las ya mencionadas tareas de corte, pelado, carga y acarreo), iniciándose así una fuerte disminución de la demanda de mano de obra para la zafra azucarera, que se había incrementado de manera notable desde la década de 1880.

${ }^{8}$ La baja cobertura del censo 2008 , inferior al $5 \%$ de la registrada en 2002 para Formosa, invalida su comparación con los resultados arrojados por los dos censos anteriores (Instituto Nacional de Estadística y Censos, 2009).

9 A diferencia de lo sucedido en la generalidad de las provincias del Chaco argentino (Salta, Chaco, Santiago del Estero, Santa Fe), el avance de la soja sobre la superficie agrícola disponible -y, de manera específica, sobre zonas típicamente algodoneras-, si bien de una tendencia manifiestamente creciente en los últimos años, no ha sido en Formosa tan dramático. Históricamente sujeta a violentas fluctuaciones -esto es, momentos de fuerte expansión intercalados con otros de igualmente fuerte contracción-, la superficie implantada con algodón más que triplicaba, en la campaña 2010-2011, aquella implantada con soja: según las estimaciones agrícolas del Ministerio de Agricultura, Ganadería y Pesca de la Nación, mientras la primera ascendía a 20.000 ha, la segunda contabilizaba 6.100 ha.

${ }^{10}$ En 1984, con la sanción de la Ley Integral del Aborigen № 426, se inició la regularización de la situación de dominio de las tierras que ocupan las comunidades indígenas. Según datos del Instituto Provincial de Colonización y Tierras Fiscales (2012), la superficie rural en manos de esas comunidades (ya fuera bajo la forma predominante de títulos comunitarios y también de títulos individuales) ascendía, en 2012, a 307.424 ha. No obstante, por cuanto la transferencia de derechos se ha limitado a áreas reducidas, la movilización indígena es aún en defensa del territorio y en torno al manejo de los recursos naturales presentes en el ámbito del frente expansivo regional.

11 En 2005, el gobierno se vio forzado a intervenir en el mercado algodonero a través de la apertura de planchadas de acopio de algodón en distintas localidades de la provincia, ante las malas perspectivas en la comercialización del cultivo.

${ }^{12}$ El término "blanco" alude a la gente no indígena, sean criollos (descendientes de aquellos procedentes de las provincias de Chaco y Corrientes y de la república del Paraguay) o de ascendencia 
europea (gringos).

${ }^{13}$ No eran pocos los programas que, a mediados de la década de 2000, asumían esa orientación: el Plan Nacional de Desarrollo Local y Economía Social "Manos a la Obra", el Programa para

\section{Referencias bibliográficas}

Althusser, L. (1976) "Contradicción y sobredeterminación". En Althusser, L. La revolución teórica de Marx. México: Siglo XXI.

Bartolomé, M. A. (1972). "La situación de los indígenas en la Argentina: área chaqueña y provincia de Misiones". En Grünberg, G. (Coord.) La situación del indígena en América del Sur (aportes al estudio de la fricción inter-étnica en los indios no-andinos), Montevideo: Tierra Nueva.

Basterra, L. (1991). Estudio económico de la cosecha mecánica del algodón comparada con la cosecha manual. Resistencia: s/d.

Borrini, H. (1987). "Colonia Bouvier: un ejemplo de colonización privada a fines del siglo XIX en el Territorio Nacional de Formosa". Cuadernos de Geohistoria Regional, № 16.

Campi, D. \& Bravo, M. C. (1999). "La agroindustria azucarera argentina. Resumen historiográfico y fuentes". América Latina en la historia económica: Boletín de fuentes. №11.

Cohen, G. (1988). History, Labour, and Freedom. Themes from Marx. Oxford: Clarendon Press.

Cordeu, E. \& Siffredi, A. (1971). De la algarroba al algodón. Movimiento mesiánico de los guaycurú. Buenos Aires: Juárez Editor.

Decreto $N^{\circ}$ 165. Emergencia ocupacional nacional. Buenos Aires: 22/01/2002.

Dirección de Análisis de Gasto Público y Programas Sociales (2009). Informe sobre los Programas de Empleo Provinciales 2008. Buenos Aires.

Geertz, C. (1999). "«Desde el punto de vista del nativo»: sobre la naturaleza del conocimiento antropológico". En Geertz, C., Conocimiento local. Ensayos sobre la interpretación de las culturas. Barcelona: Paidós.

Gordillo, G. (1995). "Después de los ingenios: la mecanización de la zafra saltojujeña y sus efectos sobre los indígenas del Chaco Centro-Occidental". Desarrollo Económico, № 137.

(2004). Landscapes of Devils. Tensions of Place and Memory in the Argentinean Chaco. Durham: Duke University Press.

Gordillo, G. \& Hirsch, S. (2010). "La presencia ausente: invisibilizaciones, políticas estatales y emergencias indígenas en la Argentina". En Gordillo G. \& Hirsch S. (Eds.) Movilizaciones indígenas e identidades en disputa en la Argentina, Buenos Aires: La Crujía.

Guy, D. (2000). "«El Rey Algodón”. Los Estados Unidos, la Argentina y el desarrollo de la industria algodonera argentina". Mundo Agrario, № 1. el Desarrollo Rural de las Provincias del Noreste Argentino y el Proyecto de Desarrollo para Pequeños Productores Agropecuarios promocionaban la producción apícola y artesanal. Ninguno de ellos se implementó entre los qom del este.

Instituto Nacional de Estadística y Censos - INDEC (2009). Censo Nacional Agropecuario 2008-CNA'08. Resultados provisorios. Instituto Provincial de Colonización y Tierras Fiscales (2012). Balance general del estado legal de las tierras de la provincia de Formosa. Año 1960-2012. Formosa: s/d.

Iñigo Carrera, J. (2013). El capital: razón histórica, sujeto revolucionario y conciencia. Buenos Aires: Imago Mundi.

(1992). El conocimiento dialéctico. La regulación de la acción en su forma de reproducción de la propia necesidad por el pensamiento. Buenos Aires: Centro para la Investigación como Crítica Práctica.

(2007). Conocer el capital hoy. Usar críticamente "El Capital". Volumen 1. Buenos Aires: Imago Mundi.

Mundi. (2008). Trabajo infantil y capital. Buenos Aires: Imago

(2012) “El capital: determinación económica y subjetividad política". Crítica Jurídica: Revista Latinoamericana de Política, Filosofía y Derecho, № 34 .

Iñigo Carrera, N. (1984). Campañas militares y clase obrera. Chaco, 1870-1930. Buenos Aires: Centro Editor de América Latina.

(1988). La violencia como potencia económica: Chaco 1870-1940. El papel del Estado en un proceso de creación de condiciones para la constitución de un sistema productivo rural. Buenos Aires: Centro Editor de América Latina.

Iñigo Carrera, V. (2008). "Sujetos productivos, sujetos políticos, sujetos indígenas: las formas de su objetivación mercantil entre los tobas del este de Formosa". Tesis de Doctorado, Facultad de Filosofía y Letras, Universidad de Buenos Aires.

(2011). "Configuraciones de la relación de ciudadanía entre los tobas de Formosa: lo universal y lo particular". Andes. Antropología e Historia, № 2.

(2013). "Trabajadores indígenas en el Chaco argentino: algunos sentidos estigmatizadores". Antípoda. Revista de Antropología y Arqueología, № 17.

(2014). "Fronteras, desarrollo y territorialidad en Argentina: a propósito de la movilización indígena en el noreste formoseño". En Trinchero, H. H., Campos Muñoz, L. \& Valverde, S. (Coords.) Pueblos indígenas, Estados nacionales y fronteras. Tensiones y paradojas de los procesos de transición contemporáneos en América Latina, Buenos Aires: Facultad de Filosofía y Letras de la Universidad de 
Buenos Aires.

Marx, K. (1968). Manuscritos: Economía y filosofía. Madrid: Alianza Editorial.

(1971) [1857-8]. Elementos fundamentales para la crítica de la economía política (borrador) 1857-1858. Buenos Aires: Siglo XXI Editores.

(1984). El Capital. Crítica de la Economía Política, Libro Tercero. México: Siglo XXI Editores.

(1999). "Formas que preceden a la producción capitalista (Acerca del proceso que precede a la formación de la relación de capital o a la acumulación originaria)". En Formaciones económicas precapitalistas, México: Siglo XXI Editores.

(2001). El Capital. Crítica de la Economía Política, Vol. I. México: Fondo de Cultura Económica.

(s/f). Miseria de la filosofía. Moscú: Ediciones en

\section{Lenguas Extranjeras.}

Menéndez, E. (2002). "El malestar actual de la antropología o la casi imposibilidad de pensar lo ideológico". Revista de Antropología Social, № 11.

Miller, E. (1979). Los tobas argentinos. Armonía y disonancia en una sociedad. México: Siglo XXI Editores.

Prieto, A. (1990). Para comprender a Formosa. Una aproximación a la historia provincial. Formosa: s/d.

Slutzky, D. (1975). Diagnóstico de la estructura social de la región NEA. Tenencia y distribución de la tierra en la región NEA. Buenos Aires: Consejo Federal de Inversiones.

Trinchero, H. (2000). Los dominios del demonio. Civilización y barbarie en las fronteras de la nación. El Chaco central. Buenos Aires: Eudeba. 